\title{
Plasmodium ovale
}

National Cancer Institute

\section{Source}

National Cancer Institute. Plasmodium ovale. NCI Thesaurus. Code C123549.

A protozoan parasite in the family Plasmodiidae. P. ovale is a rare causative agent of tertian malaria. 